\title{
Comparação entre as administrações tópica e sistêmica de oxitetraciclina no tratamento de vacas com dermatite digital papilomatosa
}

\author{
[Efficacy of topical and systemic treatments with oxytetracycline for \\ papillomatous digital dermatitis in cows] \\ M.G. Loureiro ${ }^{1}$, C.A. Rodrigues ${ }^{2 *}$, E.S. Nascimento ${ }^{3}$, C. Esteban ${ }^{4}$, S.H. Perri ${ }^{2}$, C.R. Anhesini ${ }^{5}$ \\ ${ }^{1}$ Curso de Medicina Veterinária - UNIP - Campinas, SP \\ ${ }^{2}$ Curso de Medicina Veterinária - FO-UNESP - Araçatuba, SP \\ Rua Clóvis Pestana, 793 \\ 16050-680 - Araçatuba, SP \\ ${ }^{3}$ Faculdade de Ciências Farmacêuticas - USP - São Paulo, SP \\ ${ }^{4}$ Faculdade de Ciências Médicas da Santa Casa - São Paulo, SP \\ ${ }^{5}$ Faculdade de Medicina Veterinária e Zootecnia - UNESP - Botucatu, SP
}

\begin{abstract}
RESUMO
Comparou-se a eficiência dos tratamentos tópico e sistêmico com oxitetraciclina em vacas com dermatite digital papilomatosa (DDP) e determinaram-se a presença de resíduos desse antimicrobiano no leite e sua concentração no líquido sinovial e no plasma. Utilizaram-se o tratamento tópico com oxitetraciclina em pó (grupo 1) e o sistêmico de longa ação (grupo 2) em 16 vacas holandesas em lactação, acometidas por DDP. Obtiveram-se amostras de plasma, líquido sinovial e leite nos momentos: M0, antes dos tratamentos; M1, seis horas após o tratamento e em intervalos de 12 horas até M23 (264 horas pós-tratamentos). Avaliaram-se o grau de claudicação, a extensão da lesão e a concentração da oxitetraciclina pela cromatografia líquida de alta eficiência. Nas vacas do grupo 1, ocorreu redução das lesões e da claudicação, quando comparadas com as do grupo 2. Nenhuma das amostras de leite, de líquido sinovial e de plasma nos animais do grupo 1 foi positiva para oxitetraciclina. As amostras de leite dos animais do grupo 2, entre M1 e M23, apresentaram valores acima do limite máximo residual permitido para esse antimicrobiano. $\mathrm{O}$ tratamento tópico foi eficiente no tratamento de DDP, sem produzir resíduos no leite ou concentrações no plasma e no líquido sinovial. O tratamento sistêmico foi ineficiente para DDP, resultando em resíduos no leite, durante a avaliação.
\end{abstract}

Palavras chave: bovino, pododermatite, oxitetraciclina, resíduos

\begin{abstract}
The efficacy of topical versus systemic treatment with oxytetracycline for papillomatous digital dermatitis $(P D D)$ in dairy cows was compared. Antimicrobial residues in milk and their concentrations in synovial fluid and plasma were analysed. Sixteen lactating Holstein cows with PDD lesions were topically treated with oxytetracycline powder (group 1) or long-acting oxytetracycline (group 2). Plasma, synovial fluid, and milk samples were collected in the following moments: MO (before treatments); at six hours after treatments (M1), and at 12-hour intervals until 264 hours after treatments (M23). Lameness score and lesion size were evaluated. Analysis of oxytetracycline concentration was performed by high-performance liquid chromatography $(H P L C)$. Cows in group 1 showed reduced lesion size and lameness score when compared to cows in group 2. None of the plasma, synovial fluid, or milk samples collected from cows in group 1 were positive to oxytetracycline. However, violative antimicrobial residues were detected in milk samples collected from cows in group 2, from M1 until M23. Topical application of oxytetracycline powder was an efficient treatment for PDD with no risk of violative antimicrobial residues in milk or increases its concentration in plasma or synovial fluid. The systemic administration of oxytetracycline was inefficient to treat PDD and caused violative residues in milk.
\end{abstract}

Keywords: bovine, pododermatitis, oxytetracycline, residues

Recebido em 6 de novembro de 2008

Aceito em 24 de novembro de 2009

*Autor para correspondência (corresponding author)

E-mail: celrodri@fmva.unesp.br 


\section{INTRODUÇÃO}

Dentre as diversas enfermidades podais dos bovinos, destaca-se a dermatite digital papilomatosa (DDP), doença primeiramente descrita na Itália por Cheli e Mortellaro (1974). Vários nomes têm sido utilizados para descrever a DDP, incluindo dermatite digital, papilomatose interdigital e dermatite verrucosa (Walker et al., 1995). Recentes estudos no Brasil revelaram que a ocorrência de DDP nos rebanhos pode variar de $24 \%$ (Silva et al., 2001) a 36,8\% (Silva et al., 2004). Souza et al. (2006) relataram que $87,3 \%$ dos casos de claudicação decorrem de abscessos de sola e talão, úlcera de sola e dermatite digital. Portanto, considera-se a DDP como a principal enfermidade infecciosa podal observada em rebanhos leiteiros.

A DDP apresenta-se como uma doença multifatorial em que a higiene precária é o principal fator de risco, e espiroquetas podem estar primariamente envolvidas na etiologia da doença (Fajt e Apley, 2001; Cruz et al., 2005). Recentemente, estudos imuno-histoquímicos mostraram que espécies de Treponema, Campylobacter e Fusobacterium necrophorum foram isolados a partir de lesões digitais de bovinos acometidos por DDP (Cruz et al., 2005).

As lesões iniciais são dolorosas, tipicamente avermelhadas, planas e ulceradas; posteriormente ampliam suas dimensões, adquirindo aspecto verrucoso com projeções papilares (Yeruham e Perl, 1998). Essas lesões ocorrem frequentemente nos membros pélvicos, provavelmente por suportarem maior peso e pelo maior contato com contaminantes ambientais como fezes e urina (Martins et al., 2002), e localizam-se na superfície plantar acima do espaço interdigital, adjacente aos bulbos dos cascos (Walker et al., 1995; Yeruham e Perl, 1998). A lesão determinada pela DDP pode causar claudicação moderada a severa, resultando em hiporexia com consequente diminuição da massa corporal e redução da produção leiteira (Walker et al., 1995; Britt et al., 1999), redução do ciclo estral e elevação do período compreendido entre o parto e a concepção.

Estudos revelaram que a maioria das vacas acometidas de DDP, que receberam administração tópica de penicilina $\mathrm{G}$ procaína, ceftiofur sódico, oxitetraciclina, lincomicina ou combinação de lincomicina e espectinomicina, seguida ou não de bandagens, responderam favoravelmente dentro de sete a 30 dias após o término do tratamento (Hernandez et al., 1999; Hernandez e Shearer, 2000; Laven e Proven, 2000).

Este estudo teve o objetivo de comparar a eficiência dos tratamentos tópico em pó e sistêmico com oxitetraciclina de longa ação em vacas acometidas de DDP e determinar a presença de resíduos deste antimicrobiano no leite e sua concentração no líquido sinovial e no plasma.

\section{MATERIAL E MÉTODOS}

Foram utilizadas 16 vacas, com produção média diária de 14L, entre 200 e 365 dias de lactação, com idades variando de cinco a 10 anos e pesos entre 435 e $635 \mathrm{~kg}$, confinadas em estábulo, provenientes de uma propriedade da região de Araçatuba/SP. A fazenda é endêmica para DDP. As vacas apresentavam pelo menos um membro pélvico acometido e foram consideradas positivas para a enfermidade quando apresentavam lesões dolorosas, avermelhadas, ulceradas ou proliferativas. As lesões dos animais localizavam-se na superfície plantar, acima do espaço interdigital, adjacente aos bulbos dos cascos de pelo menos um dos membros pélvicos. As vacas foram rotineiramente ordenhadas duas vezes ao dia, e todo o leite produzido no período compreendido entre o início dos tratamentos e 96 horas após o término das coletas foi descartado.

Os animais foram aleatoriamente distribuídos em dois grupos. Grupo 1, tratado com doses de $5 \mathrm{~g}$ do produto comercial, contendo $22 \%$ de cloridrato de oxitetraciclina (Tormicina Premix 220 - Tortuga Zootécnica e Agrária Belo Horizonte, MG), associado a cada troca de bandagem. Administrou-se o antimicrobiano, na forma de pó, sobre as lesões dos animais, mediante uso de compressas de gaze e ataduras de crepe (Neve Ind. Com. Prod. Cir. Ltda. - São Paulo, SP) envolvidas por fita adesiva (Silvertape - 3M do Brasil - São Paulo, SP). As bandagens foram trocadas a cada 48 horas, totalizando seis trocas. Grupo 2, tratado com doses de $20 \mathrm{mg} / \mathrm{kg}$ de peso corporal de oxitetraciclina de longa ação(Tormicina L/A - 
Tortuga), pela via intramuscular, com intervalo de aplicação de 72 horas, totalizando três aplicações. As administrações foram realizadas, alternadamente, nos músculos semitendinoso e glúteo superficial, sem que fosse ultrapassado o volume de $20 \mathrm{~mL}$ por local de aplicação.

Determinou-se o grau de claudicação, segundo a classificação de Desrochers et al. (2001), como de intensidade: 0-ausente; 1-discreto arqueamento de dorso e locomoção levemente anormal; 2-arqueamento de dorso e locomoção alterada; 3-arqueamento de dorso e claudicação marcantes e 4-relutância em se locomover e dificuldade de apoio. As lesões da DDP foram classificadas em: 1-leve; 2-moderada e 3-severa, baseando-se nos sinais e extensão da região comprometida (Walker et al., 1995; Yeruham e Perl, 1998). Todos os animais apresentavam lesões com sensibilidade e calor à palpação, previamente aos tratamentos.

Os animais, contidos em brete adaptado para casqueamento, foram mantidos em estação, sem a necessidade de tranquilização. $\mathrm{O}$ membro tratado foi elevado e posteriormente amarrado à travessa de madeira do brete. Após a contenção, procedeu-se a limpeza dos dígitos com água e sabão neutro, seguida da identificação, registro fotográfico e classificação das lesões. Os animais foram casqueados previamente aos tratamentos, sem intervir cirurgicamente na afecção, e entre os que apresentavam lesões nos dois membros pélvicos, optou-se pelo tratamento daquela mais grave.

As amostras de líquido sinovial, aproximadamente $1 \mathrm{~mL}$, foram obtidas por artrocentese seriada no espaço articular do tarso, correspondente ao membro acometido da lesão. O local da artrocentese foi precedido de tricotomia, seguido de antissepsia com solução de polivinil-pirrolidona-iodo (PVPI) (Riodeíne Ind. Farm. Rioquímica Ltda. - Rio de Janeiro, RJ) a $10 \%$. Amostras de leite, aproximadamente $50 \mathrm{~mL}$, compostas por frações retiradas equitativamente dos quatro quartos mamários, foram obtidas de todos os animais, nos momentos estabelecidos.

Colheram-se amostras de leite, líquido sinovial e plasma de cada um dos animais nos momentos: MO: imediatamente anterior ao tratamento; M1: seis horas após a administração antimicrobiano; M2: 12 horas após a administração antimicrobiano e sucessivamente, em intervalos de 12 horas, até 264 horas $\left(\mathrm{M}_{23}\right)$. As coletas em M0, M5 (48 horas), M7 (72 horas), M9 (96 horas), M13 (144 horas), M17 (192 horas) e M21 (240 horas) ocorreram previamente aos tratamentos. Ao final do período de coleta, todos os animais foram reavaliados quanto ao grau de claudicação, conforme Desrochers et al. (2001), e à extensão das lesões podais, baseando-se nos mesmos critérios inicialmente propostos. Ao término das coletas, os animais foram inspecionados durante 10 dias, com o objetivo de detectar possíveis complicações das coletas seriadas ou aplicação da oxitetraciclina injetável. As análises da concentração de oxitetraciclina foram realizadas por cromatografia líquida de alta eficiência (HPLC). Esse método mostra-se eficiente para a verificação da presença de oxitetraciclina no leite com limites de detecção a partir de $37,5 \mathrm{ng} / \mathrm{mL}$ e de quantificação a partir de 50ng/mL (Denobile e Nascimento, 2004).

Os valores da concentração de oxitetraciclina foram submetidos aos testes de Friedman, e comparações múltiplas de Dunn $(\mathrm{P}<0,05)$. Para as variáveis grau da lesão e grau de claudicação, utilizou-se o teste não paramétrico de MannWhitney para comparar os dois grupos em cada tempo de avaliação e o teste de Wilcoxon $(\mathrm{P}<0,05)$ para comparar os tempos de avaliação (pré e pós-tratamento) para cada tipo de tratamento, conforme Zar (1998), empregando-se o programa computacional SAS/1999.

\section{RESULTADOS E DISCUSSÃO}

A coleta seriada de frações contendo $1 \mathrm{~mL}$ de líquido sinovial da articulação do tarso apresentou grau de dificuldade moderado, em virtude do volume reduzido em alguns momentos, especialmente nas primeiras 24 horas. As repetidas artrocenteses facilitaram o procedimento de coleta de líquido sinovial durante o transcorrer da fase de amostragem, tornando desnecessários procedimentos de cateterização articular (Gagnon et al., 1994). Esses procedimentos frequentemente resultam na perda precoce do cateter, aumentando as dificuldades ou impossibilitando a coleta, o que leva, consequentemente, à análise incompleta dos resultados. 
A escolha da articulação do tarso para as artrocenteses seriadas apresentou resultados satisfatórios, pois todas as coletas foram produtivas ao longo do tempo, sendo este resultado atribuído ao amplo volume dessa articulação. Estudos com base na obtenção de líquido sinovial da articulação metatarsofalângica resultaram em maior dificuldade na obtenção de amostras e coletas improdutivas (Navarre et al., 1999), prejudicando significativamente a avaliação do antimicrobiano na articulação.

Nos animais do grupo 1, durante as trocas das bandagens, a oxitetraciclina em pó estava presente sobre a região acometida, indicando que apesar do intervalo de 48 horas entre cada administração, a concentração sobre as lesões permaneceu elevada. Essa característica pode ser uma das responsáveis pelo sucesso do tratamento tópico, uma vez que a dose de $5 \mathrm{~g}$ do fármaco disponibilizou $1100 \mathrm{mg}$ de cloridrato de oxitetraciclina sobre a ferida, em cada aplicação. A elevada concentração obtida pode ser comparada com a de outros tratamentos que utilizaram $5 \mathrm{~mL}$ de uma solução de tetraciclina contendo $100 \mathrm{mg} / \mathrm{mL}$, na forma de spray, três vezes ao dia, durante 21 dias (Britt et al., 1996), ou $15 \mathrm{~mL}$, duas vezes ao dia, durante sete dias (Britt et al., 1999). Hernandez et al. (1999) utilizaram solução contendo $25 \mathrm{mg} / \mathrm{mL}$, uma vez ao dia, durante 20 dias não consecutivos, sendo essa a menor concentração diária efetiva observada no tratamento da DDP, muito abaixo daquela disponibilizada no tratamento dos animais do grupo 1 .

Em outro trabalho, a solução de $100 \mathrm{mg} / \mathrm{mL}$ de tetraciclina foi aplicada sobre as lesões de DDP com o auxílio de algodão embebido com $20 \mathrm{~mL}$ do produto e bandagem. Nesse tratamento, foi realizada somente uma bandagem, mantida até a sua perda espontânea (Britt et al., 1999). Os autores não indicaram o tempo médio de permanência das bandagens, mas informaram que pode haver variação entre os animais. Nesse caso, deve-se atentar para a redução gradual da concentração de tetraciclina no algodão face às condições ambientais e de manejo dos animais. Essas observações indesejáveis não ocorreram com o uso da oxitetraciclina na forma de pó, associada à bandagem, uma vez que as trocas foram realizadas a cada 48 horas.

A recuperação das lesões influenciou diretamente na melhoria do grau de claudicação das vacas do grupo 1, resultando na ausência de sensibilidade dolorosa (Tab. 2). A recuperação frente à terapia tópica confirma os estudos, que utilizaram antimicrobianos por essa via e que obtiveram recuperação dentro de sete a 30 dias (Hernandez et al., 1999; Hernandez e Shearer, 2000; Laven e Proven, 2000).

Tabela 1. Graus de lesão apresentados pelo número (n) de animais dos grupos 1 e 2 de acordo com os momentos pré e pós-tratamento

\begin{tabular}{ccccc}
\hline Grupo & Grau da lesão & Pré-tratamento (n) & Pós-tratamento (n) & $\mathrm{P}^{1}$ \\
\hline \multirow{3}{*}{ G1 } & 0 & 0 & 8 & 0,0078 \\
& 1 & 3 & 0 & \\
& 2 & 5 & 0 & 1,0000 \\
$\mathrm{G} 2$ & 0 & 0 & 0 & \\
& 1 & 6 & 1 & \\
\hline
\end{tabular}

${ }^{1}$ teste de Wilcoxon, ${ }^{2}$ teste de Mann-Whitney $(\mathrm{P}<0,05)$.

G1: tratados com oxitetraciclina em pó; G2: tratados com oxitetraciclina longa ação sistêmica.

Grau de lesão: $0=$ ausente; $1=$ leve; $2=$ moderada; $3=$ severa. 
Comparação entre as administrações...

Tabela 2. Graus de claudicação apresentados pelo número (n) de animais dos grupos 1 e 2 de acordo com os momentos pré e pós-tratamento

\begin{tabular}{ccccc}
\hline Grupo & Grau da claudicação & Pré-tratamento & Pós-tratamento & $\mathrm{P}^{1}$ \\
\hline \multirow{3}{*}{ G1 } & 0 & 0 & 7 & \\
& 1 & 0 & 0 & 0,0156 \\
& 2 & 5 & 0 & \\
& 3 & 3 & 0 & 0,0625 \\
& 4 & 0 & 0 & \\
\hline \multirow{3}{*}{ G2 } & 0 & 0 & 0 & \\
& 1 & 5 & 6 & \\
& 2 & 2 & 1 & \\
& 3 & 1 & 0,0014
\end{tabular}

teste de Wilcoxon, ${ }^{2}$ teste de Mann-Whitney $(\mathrm{P}<0,05)$.

G1: tratados com oxitetraciclina em pó; G2: tratados com oxitetraciclina longa ação sistêmica.

Grau de claudicação: $0=$ ausente; $1=$ discreto arqueamento de dorso e locomoção levemente anormal; $2=$ arqueamento de dorso e locomoção alterada; 3 = arqueamento de dorso e claudicação marcantes; $4=$ relutância em se locomover e dificuldade de apoio.

O tratamento tópico com oxitetraciclina mostrouse eficiente na vaca 402, contudo esse animal apresentou aumento do grau de claudicação de três para quatro. Este resultado deveu-se à ocorrência de um abscesso subsolear no dígito lateral do membro acometido pela lesão. Provavelmente não houve correlação entre a lesão de DDP e o abscesso, uma vez que as principais complicações da DDP são erosão de talão, úlcera de sola, crescimento excessivo do casco, associadas frequentemente a miíases e necrose (Martins et al., 2002), afecções essas não observadas nessa vaca.

As oscilações observadas nas concentrações da oxitetraciclina plasmática e do líquido sinovial, por vezes abaixo da concentração inibitória mínima (CIM) (Fig. 1 e 2), após 48 horas de cada administração, provavelmente se refletem na pele acometida pela DDP. Esse comportamento não ocorreu no tratamento tópico, em que o antimicrobiano permaneceu em contato direto com o tecido lesado de forma ininterrupta. Devese considerar, ainda, que os tratamentos com oxitetraciclina tópica, comprovadamente, apresentam resultados altamente satisfatórios, especialmente se executados por períodos de sete
(Britt et al., 1999) a 30 dias (Britt et al., 1996; Hernandez et al., 1999). Contudo, deve-se considerar que esses tratamentos foram aplicados na forma de spray e, assim, a concentração de tetraciclina sobre a lesão pode sofrer variações devido às condições ambientais e de manejo dos animais.

Somente uma vaca do grupo 2, tratada com oxitetraciclina sistêmica, recuperou-se parcialmente da lesão (Tab. 1). O grau de claudicação aumentou em cinco animais do grupo 2, seis horas após a primeira aplicação de oxitetraciclina, fato atribuído à reação inflamatória acentuada nos locais de administração, o que dificulta a observação da correlação do grau de claudicação nos momentos avaliados e as demais variáveis. Essa alteração foi observada a cada nova aplicação, estendendose por 10 dias, após o último momento de coleta.

Os picos de concentração da tetraciclina no plasma dos animais do grupo 2, após a administração de $20 \mathrm{mg} / \mathrm{kg}$, alcançaram valores de 4390,67 (M2), 4453,17 (M8) e 4361,50ng/mL (M14), enquanto as concentrações no líquido sinovial foram de $1766,47,1947,88$ e 
2037,86ng/mL nos mesmos momentos. Os picos ocorreram 12 horas após cada aplicação. Landoni e Errecalde (1992) obtiveram picos de concentração mais baixos, após a administração intramuscular de $20 \mathrm{mg} / \mathrm{kg}$ de oxitetraciclina. O valor observado no soro foi de $1680 \mathrm{ng} / \mathrm{mL}$ e no líquido sinovial de $730 \mathrm{ng} / \mathrm{mL}$, após 12 e 24 horas, respectivamente. Esses valores podem ser comparados com os encontrados a partir da administração de uma única dose de $10 \mathrm{mg} / \mathrm{kg}$ de cloridrato de tetraciclina cristalina pela via IV, que resultou em concentrações de $10662,94 \mathrm{ng} / \mathrm{mL}$ e $3471,57 \mathrm{ng} / \mathrm{mL}$, no plasma e no líquido sinovial, após 22 minutos e 1 hora e 22 minutos (Rodrigues, 2003). Essa ampla disparidade entre os resultados pode ser atribuída às diferenças químicas entre as tetraciclinas administradas pelos autores, vias de aplicação e veículos dos produtos, que interferem na sua distribuição e concentração.

Os resultados insatisfatórios no tratamento da DDP, obtidos a partir da administração sistêmica de oxitetraciclina, evidenciaram-se pela manutenção do grau de severidade da lesão manifestado em sete animais, aspectos descritos por Yeruham e Perl (1998). Somente um animal do grupo 2 apresentou melhoria da lesão, passando do grau moderado para o leve. Estas observações divergem dos relatos que atribuem redução significativa das lesões causadas pela DDP quando da administração tópica ou parenteral de alguns antimicrobianos (Hernandez et al., 1999; Laven e Proven, 2000; Fajt e Apley, 2001).

Outra razão para o baixo sucesso do tratamento com a oxitetraciclina sistêmica pode, em parte, ser atribuído às concentrações abaixo de 250ng/mL, obtidas no líquido sinovial, decorridas aproximadamente 48 horas de cada uma das três aplicações (Fig. 2) em M6, M7, M13 e M19 (Tab. 3). As concentrações de oxitetraciclina no líquido sinovial e, provavelmente, nos tecidos que compõem o dígito, permaneceram abaixo de $250 \mathrm{ng} / \mathrm{mL}$, durante aproximadamente 12 horas antes da segunda e terceira aplicações. Este resultado reveste-se de grande importância clínica, pois, nas enfermidades podais, além da dificuldade de distribuição adequada do antibiótico, devido à morfologia dos tecidos envolvidos, ocorre ainda inflamação, que favorece a permanência de microrganismos (Anderson et al., 1996; Trent e Redic-Kill, 1997).

Contudo, concentração local de $363355,14 \mathrm{ng} / \mathrm{mL}$, obtida a partir da administração intravenosa regional, mostrou-se incapaz de curar animais acometidos de DDP. Uma das explicações para a ineficiência desse tratamento foi o período reduzido de 12 horas em que a concentração do antimicrobiano se manteve acima do limite de $250 \mathrm{ng} / \mathrm{mL}$, conforme já relatou Rodrigues (2003). Esse valor é tido como a CIM de tetraciclina para bactérias patogênicas frequentemente encontradas em processos infecciosos (Finch, 1997; Silva et al., 1999). Assim, esperavam-se neste estudo resultados satisfatórios com o tratamento parenteral, devido às concentrações se manterem acima desse limite por 48 horas após cada aplicação.

Os picos da concentração de tetraciclina no líquido sinovial foram de 2064,40 (M2), 1947,88 (M8) e 2037,86ng/mL (M14). Estudo in vitro, com bovinos acometidos de enfermidades podais, demonstrou a susceptibilidade de Arcanobacterium pyogenes à penicilina, à amoxacilina, à eritromicina, à lincomicina e a tetraciclinas, com relativa resistência bacteriana à oxitetraciclina, em que a CIM, capaz de inibir o crescimento de $50 \%$ das bactérias (CIM50) foi 6250ng/mL e a CIM90 (capacidade de inibir o crescimento de $90 \%$ das bactérias) de $25000 \mathrm{ng} / \mathrm{mL}$. Desse modo, caracteriza-se a resistência bacteriana à oxitetraciclina devido aos elevados valores das CIM50 e CIM90. Os picos da concentração obtidos no líquido sinovial, com o tratamento sistêmico, neste estudo, encontramse abaixo das CIM, previamente estabelecidas (Landoni e Errecalde, 1992), justificando, em parte, a ineficiência da terapia parenteral com oxitetraciclina, desconsiderando-se a resistência bacteriana ao antimicrobiano nos animais avaliados.

A concentração tecidual no local das lesões, reflexo dos valores obtidos no plasma e líquido sinovial (Fig. 1 e 2), provavelmente foi suficiente para reduzir o processo infeccioso em um dos animais estudados, pois houve recuperação parcial da lesão. 
Comparação entre as administrações...

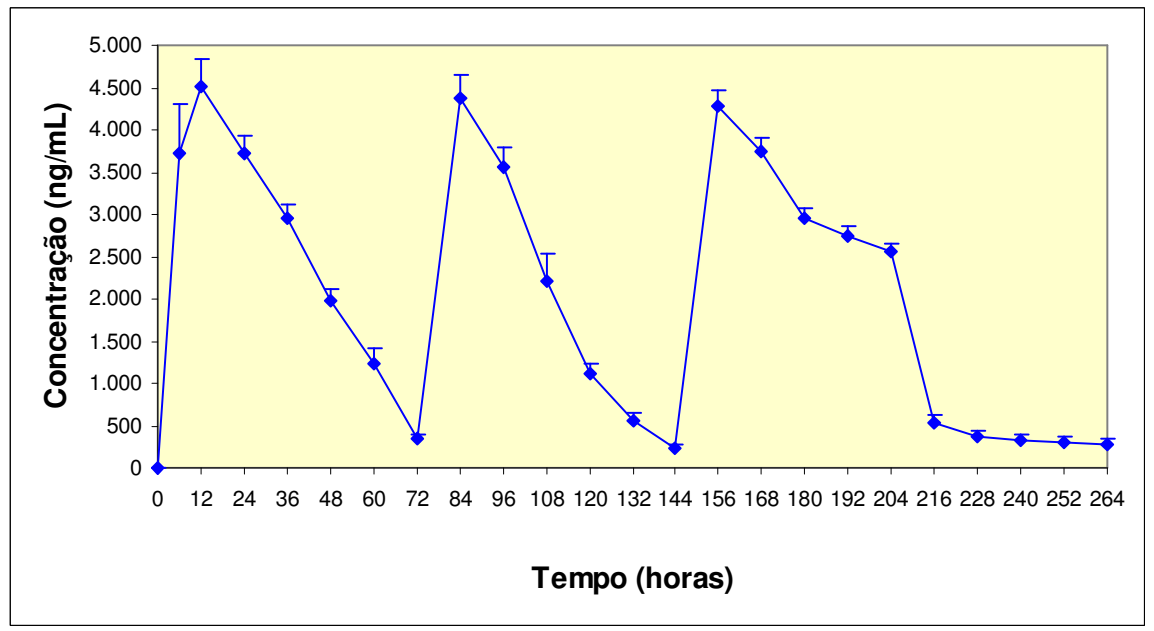

Figura 1. Concentração média de oxitetraciclina $(\mathrm{ng} / \mathrm{mL})$ no plasma de vacas tratadas $(20 \mathrm{mg} / \mathrm{kg} / \mathrm{peso}$ corporal - 0, 72 e 144h) por via sistêmica.

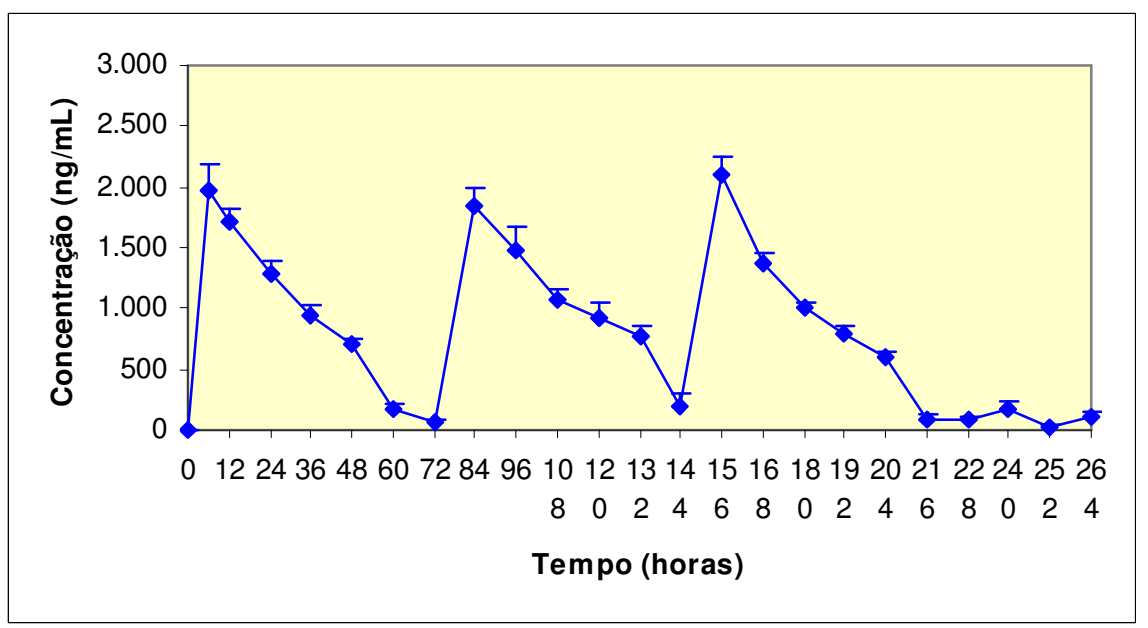

Figura 2. Concentração média de oxitetraciclina $(\mathrm{ng} / \mathrm{mL})$ no líquido sinovial de vacas tratadas $(20 \mathrm{mg} / \mathrm{kg} /$ peso corporal - 0, 72 e $144 \mathrm{~h})$ por via sistêmica.

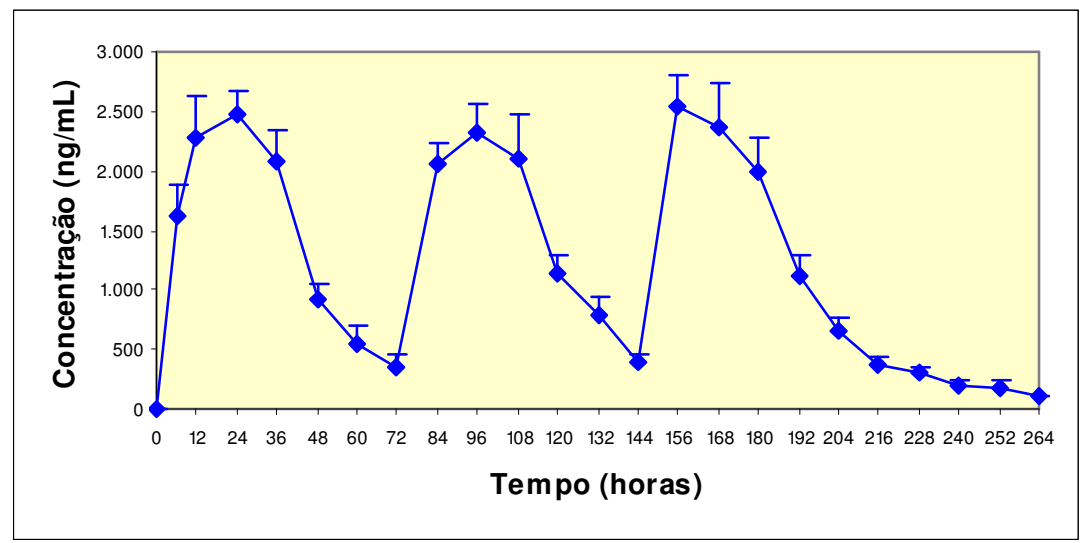

Figura 3. Valores da concentração média de oxitetraciclina (ng/mL) no leite de vacas tratadas $(20 \mathrm{mg} / \mathrm{kg} /$ peso corporal - 0, 72 e $144 \mathrm{~h})$, por via sistêmica. 


\section{Loureiro et al.}

Tabela 3. Medianas da concentração de oxitetraciclina, por momento, no leite, no líquido sinovial e no plasma de vacas acometidas por dermatite digital papilomatosa, tratadas com oxitetraciclina parenteral $(20 \mathrm{mg} / \mathrm{kg} /$ peso corporal $-0,72,144 \mathrm{~h})$

\begin{tabular}{|c|c|c|c|}
\hline \multirow{2}{*}{$\begin{array}{l}\text { Momento } \\
\text { (horas) }\end{array}$} & \multicolumn{3}{|c|}{ Concentração ng/mL (Mediana) } \\
\hline & Plasma & Líquido sinovial & Leite \\
\hline M0 & $0,00 \mathrm{e}$ & $0,00 \mathrm{f}$ & $0,00 \mathrm{e}$ \\
\hline M1 (6) & 3999,00abc & $2064,40 a$ & 1591,53abcd \\
\hline M2 (12) & $4390,67 \mathrm{a}$ & $1766,47 \mathrm{a}$ & $2041,74 \mathrm{ab}$ \\
\hline M3 (24) & $3544,84 a b c$ & $1316,62 \mathrm{abcd}$ & $2409,67 \mathrm{a}$ \\
\hline M4 (36) & $2890,67 \mathrm{abcd}$ & $885,94 \mathrm{abcdef}$ & 2161,96abcd \\
\hline M5 (48) & 1874,00abcde & 703,05abcdef & 932,49abcde \\
\hline M6 (60) & 1161,50abcde & 179,45 bcdef & $538,87 \mathrm{abcde}$ \\
\hline M7 (72) & $361,50 \mathrm{de}$ & $43,76 \mathrm{ef}$ & 202,27 cde \\
\hline M8 (84) & $4453,17 \mathrm{a}$ & $1947,88 \mathrm{a}$ & 2227,95abcd \\
\hline M9 (96) & $3703,17 \mathrm{abc}$ & $1313,67 \mathrm{ab}$ & $2268,12 \mathrm{ab}$ \\
\hline M10 (108) & 1961,50abcde & $1005,41 \mathrm{abcde}$ & $1810,97 \mathrm{abcd}$ \\
\hline M11 (120) & 1182,34 abcde & $894,79 \mathrm{abcdef}$ & $1176,73 \mathrm{abcde}$ \\
\hline M12 (132) & 544,84 bcde & $694,20 \mathrm{abcdef}$ & $656,98 \mathrm{abcde}$ \\
\hline M13(144) & $219,84 \mathrm{de}$ & $61,45 \mathrm{bcdef}$ & 359,44 bcde \\
\hline M14 (156) & $4361,50 \mathrm{a}$ & $2037,86 a$ & $2253,76 a$ \\
\hline M15 (168) & $3628,17 \mathrm{abc}$ & $1372,66 \mathrm{abc}$ & $1879,57 \mathrm{ab}$ \\
\hline M16 (180) & $3069,84 \mathrm{abcd}$ & 1014,26abcde & $1628,56 \mathrm{abcd}$ \\
\hline M17 (192) & $2828,17 \mathrm{abcd}$ & $834,32 \mathrm{abcdef}$ & 997,70abcde \\
\hline M18 (204) & 2624,00abcde & $605,70 \mathrm{abcdef}$ & 609,60abcde \\
\hline M19 (216) & 557,34 bcde & $80,63 \mathrm{def}$ & 403,42 bcde \\
\hline M20 (228) & 394,84 cde & $77,68 \mathrm{def}$ & 326,36 cde \\
\hline M21 (240) & $374,00 \mathrm{de}$ & $83,58 \mathrm{cdef}$ & $198,29 \mathrm{de}$ \\
\hline M22 (252) & $344,84 \mathrm{de}$ & $23,35 \mathrm{ef}$ & $121,76 \mathrm{de}$ \\
\hline M23 (264) & 344,84 de & $15,73 \mathrm{def}$ & $99,59 \mathrm{de}$ \\
\hline
\end{tabular}

Momentos seguidos por letra distinta na coluna diferem entre si pelo teste Dunn $(\mathrm{P}<0,05)$.

A concentração da tetraciclina nos músculos, ossos, articulações e pele é resultado direto da concentração sérica. Apesar de útil em certas circunstâncias e basear-se no princípio de que a concentração tecidual é reflexo direto da concentração sérica do antimicrobiano, distorções dessa correlação podem ocorrer (Fajt e Apley, 2001; Rodrigues, 2003). Nas vacas do grupo 2, também se observou paralelismo farmacocinético, pois a concentração sérica reflete-se, de forma diretamente proporcional, na concentração do líquido sinovial, conforme observado por Navarre et al. (1999). Contudo, houve baixa difusão de oxitetraciclina do plasma para o líquido sinovial, possivelmente resultado da dificuldade na penetração e distribuição articular, uma vez que os valores da concentração no líquido sinovial foram muito abaixo dos encontrados no plasma (Fig. 1 e 2). Este resultado revela que a concentração 
plasmática de um determinado antimicrobiano deve ser extrapolada com ressalvas para o tratamento de infecções que envolvam outros sistemas, particularmente o aparelho locomotor.

Nas vacas tratadas do grupo 1, não foram detectados resíduos no leite. Britt et al. (1999), ao utilizarem oxitetraciclina em solução aquosa, administrada sob a forma de spray ou bandagem com algodão embebido, também não detectaram resíduos por HPCL no leite de vacas acometidas por DDP, tratadas por via tópica. A análise negativa para oxitetraciclina no plasma pode justificar sua ausência no líquido sinovial e leite, seguindo o conceito de paralelismo farmacocinético (Fajt e Apley, 2001).

O leite produzido pelos animais do grupo 2 estaria fora dos padrões regulamentares por, pelo menos, 120 horas após a última administração (Fig. 3), pois os limites máximos residuais (LMR) estabelecidos pelo Plano Nacional de Resíduos Biológicos em Produtos de Origem Animal são de $100 \mathrm{ng} / \mathrm{mL}$ para esse antibiótico (Instrução..., 1999). A presença desses resíduos no leite pode causar reações alérgicas em indivíduos sensíveis e selecionar cepas bacterianas resistentes nos seres humanos.

O leite dos animais do grupo 1 poderia ser consumido durante todo o tratamento, pois as análises da concentração de oxitetraciclina, em todos os momentos, mostraram valores abaixo dos limites de detecção a partir de 37,5ng/mL, estabelecidos pelo HPLC (Denobile e Nascimento, 2004) e, consequentemente, abaixo do limite de 100ng/mL (Instrução..., 1999). Este resultado confirma os resultados obtidos por Britt et al. (1999), quando do tratamento com oxitetraciclina em spray, em que os valores residuais não atingiram os limites de 3,5 a $12 \mathrm{ng} / \mathrm{mL}$ em 48 amostras avaliadas pelo screening test e HPLC.

\section{CONCLUSÕES}

A oxitetraciclina em pó associada à bandagem mostrou-se eficiente no tratamento de vacas acometidas por DDP, enquanto a terapia sistêmica de longa ação, utilizando o mesmo antimicrobiano, foi ineficiente após três aplicações. $\mathrm{O}$ tratamento tópico não apresentou níveis detectáveis de oxitetraciclina por HPLC no plasma, no líquido sinovial e no leite, o que permitiria o consumo do leite durante todo o período de tratamento. O leite dos animais tratados com oxitetraciclina por via sistêmica deveria ser descartado por pelo menos 120 horas após a terceira administração, e sua aplicação deveria ser a cada 48 horas.

\section{AGRADECIMENTOS}

À Fundação de Amparo à Pesquisa do Estado de São Paulo (FAPESP), processos 2005/02462-5, 2007/06334-7 e 2008/02715-9, pelas concessões de auxílio financeiro à pesquisa, reunião no Brasil e reunião no exterior, respectivamente e a TORTUGA Companhia Zootécnica Agrária, pelo custeio parcial projeto.

\section{REFERÊNCIAS BIBLIOGRÁFICAS}

ANDERSON, D.E.; ST-JEAN, G.; MORIN, D.E. et al. Traumatic flexor tendon injuries in 27 cattle. Vet. Surg., v.25, p.320-326, 1996.

BRITT, J.S.; GASKA, J.; GARRET, E.F. et al. Comparison of topical application of three products for treatment of papillomatous digital dermatitis in dairy cattle. J. Am. Vet. Med. Assoc., v.209, p.1134-1136, 1996.

BRITT, J.S.; CARSON, M.C.; VON BREDOW, J.D. et al. Antibiotic residues in milk samples obtained from cows after treatment for papillomatous digital dermatitis. J. Am. Vet. Med. Assoc., v.215, p.833-836, 1999.

CHELI, R.; MORTELLARO, C.M. La dermatite digitale del bovino. In: CONFERENCE ON DESEASE OF CATTLE, 8., 1974, Milan. Proceedings... Milan: [s.n.], 1974. p.208-213.

CRUZ, C.E.; PESCADOR, C.A.; NAKAJIMA, $Y$. et al. Immunopathological investigations on bovine digital epidermitis. Vet. Rec., v.157, p.834-840, 2005.

DENOBILE, M.; NASCIMENTO, E.S. Validação de método para determinação de resíduos dos antibióticos oxitetraciclina, tetraciclina, clortetraciclina e doxiciclina, em leite, por cromatografia líquida de alta eficiência. Rev. Bras. Cienc. Farm., v.40, p.209-218, 2004.

DESROCHERS, A.; ANDERSON, D.E.; STJEAN, G. Lameness examination in cattle. Vet. Clin. N. Am. Food Anim. Pract., v.17, p.39-51, 2001. 
FAJT, V.R.; APLEY, M.D. Antimicrobial issues in bovine lameness. Vet. Clin. N. Am. Food Anim. Pract., v.17, p.159-174, 2001.

FINCH, R.G. Tetracyclines. In: O'GRADY, F.; LAMBERT, H.P. (Ed.). Antibiotic and chemotherapy: Anti-infective agents and their use in therapy. 7.ed. London: Churchill Livingstone, 1997. p.469-484.

GAGNON, H.; FERGUSON, J.G.; PAPICH, M.G. et al. Single-dose pharmacokinetics of cefazolin in bovine synovial fluid after intravenous regional injection. J. Vet. Pharmacol. Ther., v.17, p.31-37, 1994.

HERNANDEZ, J.; SHEARER, J.K. Efficacy of oxytetracycline for treatment of papillomatous digital dermatitis lesions on various anatomic locations in dairy cows. J. Am. Vet. Med. Assoc., v.216, p.1288-1290, 2000.

HERNANDEZ, J.; SHEARER, J.K.; ELLIOTT, J.B. Comparison of topical application of oxytetracycline and four nonantibiotic solutions for treatment of papillomatous digital dermatitis in dairy cows. J. Am. Vet. Med. Assoc., v.214, p.688-690, 1999.

INSTRUÇÃO Normativa $\mathrm{n}^{\circ} 42$, de 20 de Dezembro de 1999. O Ministério da Agricultura, do Abastecimento e da Reforma Agrária estabelece o Programa de Controle e Resíduos Biológicos em Leite (PCRBL). Diário Oficial da União, Brasília, 22 dez. 1999. Seção 1, p.213.

LANDONI, M.F.; ERRECALDE, J.O. Tissue concentrations of a long-acting oxytetracycline formulation after intramuscular administration in cattle. Rev. Sci. Tech., v.11, p.909-915, 1992.

LAVEN, R.A.; PROVEN, M.J. Use of an antibiotic footbath in the treatment of bovine digital dermatitis. Vet. Rec., v.147, p.503-506, 2000 .

MARTINS, C.F.; SARTI, E., BUSATO, I. et al. Prevalência e classificação das afecções podais em vacas lactantes na bacia leiteira de Campo Grande - MS e municípios arredores. Ensaios Cienc., v.6, p.113-137, 2002.

NAVARRE, C.B.; ZHANG, L.; SUNKARA, G. et al. Ceftiofur distribution in plasma and joint fluid following regional limb injection in cattle. J. Vet. Pharmacol. Ther., v.22, p.13-19, 1999.
RODRIGUES, C.A. Comparação entre as concentrações de oxitetraciclina no plasma, líquido sinovial e leite de vacas acometidas de dermatite digital papilomatosa, submetidas a administração intravenosa e intravenosa regional. 2003. 102f. Tese (Doutorado) Faculdade de Medicina Veterinária e Zootecnia, Universidade Estadual Paulista, Botucatu, SP.

SILVA, C.A.; SILVA, L.A.F.; MESQUITA, A.J. et al. Microbiota anaeróbia isolada de bovinos com pododermatite. Arq. Bras. Med. Vet. Zootec., v.51, p.207-212, 1999.

SILVA, L.A.F.; FIORAVANTI, M.C.S.; TRINDADE, B.R. et al. Enfermidades digitais em vacas de aptidão leiteira: Associação com mastite clínica, metrite e aspectos epidemiológicos. Pesq. Vet. Bras., v.24, p.217222, 2004

SILVA, L.A.F.; SILVA, L.M.; ROMANI, A.F. et al. Características clínicas e epidemiológicas das enfermidades podais em vacas lactantes no município de Orizona - GO. Cienc. Anim. Bras., v.2, p.119-126, 2001.

SOUZA, R.C.; FERREIRA, P.M.; MOLINA, L.R. et al. Perdas econômicas ocasionadas pelas enfermidades podais em vacas leiteiras confinadas em sistema free stall. Arq. Bras. Med. Vet. Zootec., v.58, p.982-987, 2006.

TRENT, A. M.; REDIC-KILL, K.A. Clinical pharmacology. In: GREENOUGH, P.R.; WEAVER, A.D. (Ed.). Lameness in cattle. 3.ed. Philadelphia: W.B. Saunders, 1997. p.56-70.

YERUHAM, I.; PERL, S. Clinical aspects of an outbreak of papillomatous digital dermatitis in a dairy cattle herd. J. S. Afr. Vet. Assoc., v.69, p.112-115, 1998.

WALKER, R.L.; READ, D.H.; LORETZ, K.J. et al. Spirochetes isolated from dairy cattle with papillomatous digital dermatitis and interdigital dermatitis. Vet. Microbiol., v.47, p.343-355, 1995.

ZAR, J.H. Biostatistical analysis. 4.ed. Upper Saddle River, NJ: Prentice-Hall, 1998. 930p. 